NBER WORKING PAPER SERIES

\title{
RATIONAL INATTENTION: A SOLUTION TO THE FORWARD DISCOUNT PUZZLE
}

\author{
Philippe Bacchetta \\ Eric van Wincoop \\ Working Paper 11633 \\ http://www.nber.org/papers/w11633
NATIONAL BUREAU OF ECONOMIC RESEARCH 1050 Massachusetts Avenue
Cambridge, MA 02138
September 2005

We would like to thank Gianluca Benigno and participants at an RTN International Capital Markets meeting and seminar participants at the universities of Illinois and St Gallen and the Hong Kong Monetary Authority. We also thank Elmar Mertens for outstanding research assistance. Van Wincoop acknowledges financial support from the Bankard Fund for Political Economy and the Hong Kong Institute for Monetary Research. Support from the National Centre of Competence in Research "Financial Valuation and Risk Management" (NCCR FINRISK) is also gratefully acknowledged. The NCCR FINRISK is a research program supported by the Swiss National Science Foundation. The views expressed herein are those of the author(s) and do not necessarily reflect the views of the National Bureau of Economic Research.

(C)2005 by Philippe Bacchetta and Eric van Wincoop. All rights reserved. Short sections of text, not to exceed two paragraphs, may be quoted without explicit permission provided that full credit, including (C) notice, is given to the source. 
Rational Inattention: A Solution to the Forward Discount Puzzle

Philippe Bacchetta and Eric van Wincoop

NBER Working Paper No. 11633

September 2005

JEL No. F3, G1, E4

\section{$\underline{\text { ABSTRACT }}$}

The uncovered interest rate parity equation is the cornerstone of most models in international macro. However, this equation does not hold empirically since the forward discount, or interest rate differential, is negatively related to the subsequent change in the exchange rate. This forward discount puzzle is one of the most extensively researched areas in international finance. It implies that excess returns on foreign currency investments are predictable. In this paper we propose a new explanation for this puzzle based on rational inattention. We develop a model where investors face a cost of collecting and processing information. Investors with low information processing costs trade actively, while other investors are inattentive and trade infrequently. We calibrate the model to the data and show that (i) inattention can account for most of the observed predictability of excess returns in the foreign exchange market, (ii) the benefit from frequent trading is relatively small so that few investors choose to be attentive, (iii) average expectational errors about future exchange rates are predictable in a way consistent with survey data for market participants, and (iv) the model can account for the puzzle of delayed overshooting of the exchange rate in response to interest rate shocks.

Philippe Bacchetta

Study Center Gerzensee

Dorfstr. 2 P.O. Box 21

CH-3115 Gerzensee

SWITZERLAND

phbacchetta@szgerzensee.ch
Eric Van Wincoop

Department of Economics

University of Virginia

P.O. Box 400182

Charlottesville, VA 22904-4182

and NBER

vanwincoop@virginia.edu 


\section{Introduction}

One of the best established puzzles in international finance is the forward discount puzzle. Fama (1984) illuminated the problem with a regression of the monthly change in the exchange rate on the preceding one-month forward premium. The uncovered interest rate parity equation, which is the cornerstone of many models in international macro, implies a coefficient of one. But surprisingly Fama found a negative coefficient for each of nine different currencies. This evidence implies that excess returns on foreign currency investment are predictable. ${ }^{1}$ Using more recent data from 1978 to 2004, panel A of Table 1 presents evidence for the average of 5 currencies against the US dollar. A regression of the 3-month excess return of a foreign currency investment on the preceding 3-month forward discount yields an average coefficient of $-2.5 .^{2}$ Similar evidence of excess return predictability has been extensively documented for stock and bond markets. While there are potential statistical problems in these predictability regressions, they do not fully explain the results. ${ }^{3}$

In this paper we focus on the foreign exchange market. Two sets of explanations for the forward discount puzzle have been proposed in the literature: time-varying risk premia and predictable expectational errors. In the first approach, the risk premium is both time varying and negatively correlated with the forward premium. Numerous studies have attempted to implement this explanation, but so far have fallen short of explaining the puzzle. ${ }^{4}$ In the second approach investors make

\footnotetext{
${ }^{1}$ For surveys see Lewis (1995) and Engel (1996). Some of the more recent contributions on the forward discount puzzle include Backus, Foresi and Telmer (2001), Beakert, Hodrick and Marshall (1997), Chaboud and Wright (2005), Chinn and Meredith (2005), Chinn and Frankel (2002), Fisher (2005), Flood and Rose (2001), Gourinchas and Tornell (2004), Mark and Wu (1998) and Sarno, Valente and Leon (2004). Sarno (2005) provides a recent survey.

${ }^{2}$ The regression in Panel A of Table 1 is $q_{t+1}=\alpha+\beta f d_{t}+u_{t+1}$ where $q_{t+1}=s_{t+1}-s_{t}-f d_{t}$ is the excess return on an investment in foreign currency, $s_{t}$ is the log nominal exchange rate and $f d_{t}$ is the forward discount.

${ }^{3}$ The main statistical problems of excess return regressions relate to small sample bias and bias caused by the persistence of right hand side variables (e.g. forward discount, interest rate or dividend yield). However, these problems usually can only explain a part of the total bias. See, for example, Stambaugh (1999), Campbell and Yogo (2005), or Liu and Maynard (2005).

${ }^{4}$ See the surveys by Lewis (1995) and Engel (1996), which reach this conclusion. Bekaert, Hodrick and Marshall (1997) find that even a model with first-order risk aversion, in which risk-premia are very volatile, cannot account for the evidence.
} 
predictable expectational errors about future exchange rates that are negatively correlated with the forward premium. Froot and Frankel (1989) use exchange rate survey data to show that this can explain the entire forward discount bias. Using an updated data set, Panel B of Table 1 presents evidence for 5 currencies showing that expectational errors by market participants about future exchange rates continue to be highly predictable by the forward discount. ${ }^{5}$ While the empirical evidence appears more consistent with this second explanation, many researchers feel uneasy because predictable expectational errors appear to imply deviations from rationality.

In this paper we propose an explanation for the forward discount puzzle where investors are rational, but may make predictable expectational errors. There are significant costs associated both with collecting information, processing information and making decisions based on that information. These costs are added to the usual transaction costs. This makes it optimal for many investors to only infrequently assess available information and revise portfolios. ${ }^{6}$ Investors may therefore be rationally inattentive, which gives rise to predictable expectational errors. Froot and Thaler (1990) and Lyons (2001) have informally argued that models where some agents are slow in responding to new information may explain the forward discount puzzle. Here we formally show that a model with rational inattention calibrated to the data can explain the forward bias puzzle. In a companion paper (Bacchetta and van Wincoop, 2005), we show that a similar mechanism can

\footnotetext{
${ }^{5}$ The survey data is from Forecasts Unlimited Inc. It is based on monthly forecasts by 43 financial institutions from 1986 to 2004. See Bacchetta, Mertens, and van Wincoop (2005) for more details.

${ }^{6}$ Transaction costs are fundamentally different in that they are only incurred if assets are traded. After observing the state of nature each period, investors can decide whether to trade or not. These are state-dependent decision rules. By contrast, information processing costs are incurred whether the resulting information leads to any transactions or not. In contrast to transaction costs, the decision about when to incur these costs is not based on current information, but on past information. They lead to time-dependent decision rules, whereby investors process information infrequently and decide in advance when to process information next. The two types of costs can interact though. When there are information processing costs, investors process information less frequently when they also face transaction costs. Baldwin (1990) studies deviations from uncovered interest rate parity that arise as a result of transaction costs alone. In that case investors do not make predictable expectational errors since they continuously process all available information.
} 
explain excess return predictability in the stock market.

While it is well recognized that individual investors often trade infrequently and make infrequent portfolio decisions, ${ }^{7}$ it is less obvious that such inattention would not be largely unraveled by institutions that trade very actively on the market. There are nonetheless good reasons to believe that such unraveling by attentive traders only takes place to a limited extent. First, the most active institutions in terms of trading volume tend to own only a small fraction of the wealth. For example, two thirds of trade in the foreign exchange market is done among banks that are foreign exchange dealers (BIS, 2004). These dealers follow the markets very closely during the course of a trading day, but hold very little foreign exchange overnight. Hedge funds are also extremely active, but still represent only a small share of financial wealth. ${ }^{8}$ Second, while some mutual funds trade very actively on the market, by law these trades are severely restricted to the asset class defined by the fund. They generally have little room in terms of switching between domestic and foreign securities. Those decisions are ultimately made by the investors in the mutual funds themselves. Finally, the ability of attentive investors to exploit expected profit opportunities is reduced both by risk-aversion and the significant uncertainty surrounding future exchange rate changes. While excess returns are predictable, the $R^{2}$ of such regressions tends to be small.

Our theoretical analysis is related to recent developments in the stock market literature. On the one hand, several studies show how asset allocation is affected by predictability. ${ }^{9}$ On the other hand, some recent papers examine the impact

\footnotetext{
${ }^{7}$ See Bacchetta and van Wincoop (2005) for a description of infrequent trading and decision making in the stock market. The far majority of investors does not make any transactions during a particular year, either regarding directly held stocks or mutual fund investments. As many as $85 \%$ of investors report that they follow a buy-and-hold strategy. Systematic evidence is typically not recorded for the foreign exchange market, but trade in the foreign exchange market is closely related to international trade in stocks, bonds and other assets. Infrequent portfolio reallocation across markets is consistent with the evidence of Froot, O'Connell, and Seasholes (2001). They show that cross-country equity flows react with lags to a change in returns, while the contemporaneous reaction is muted.

${ }^{8}$ Based on data reported by Hedge Fund Research, in 2003 total assets under management worldwide by hedge funds represented less than $1 \%$ of U.S. financial wealth.

${ }^{9}$ See for example Kandel and Stambaugh (1996), Campbell and Viceira (1999), or Barberis (2000).
} 
of infrequent trading due to limited attention in asset markets. ${ }^{10}$ However, the literature has not linked predictability with infrequent trading: those papers that examine the impact of predictability assume it exogenous, while papers that examine infrequent trading do not examine its impact on asset prices. Our paper departs from the existing literature by incorporating both predictability and rational inattention and by showing that the latter can cause the former. ${ }^{11}$

We develop a model for the foreign exchange market with two key features. First, it is a general equilibrium model where the exchange rate is determined endogenously. This endogeneity is critical to shed light on excess return predictability. Second, investors choose whether to be attentive or inattentive. Attentive investors make portfolio decisions each period, but face a periodic cost of doing so. Inattentive investors make infrequent portfolio decisions. Investors choose to be inattentive when the welfare gain from frequent portfolio decisions is less than the associated cost. The decision to be inattentive is therefore perfectly rational as investors need to take into account the opportunity cost associated with frequent information processing and decision making. Investors who face a relatively low cost of information processing will choose to be attentive, while others choose to be inattentive. Inattention leads to a delay by which new information is reflected in the exchange rate, causing predictable excess returns.

We calibrate the model to data for five industrialized countries on which the empirical evidence in Table 1 is based. The main results can be summarized as follows. First, in equilibrium only a small portion of investors will find it worthwhile to be attentive. We find that it is optimal for $95 \%$ of investors to make portfolio decisions only once in 5 quarters when they face an annual information processing cost of at least $2.4 \%$ of financial wealth. This is less than what is charged by most hedge funds, for example. The remaining investors have a lower information processing cost and make portfolio decisions every quarter. Second, a regression of the quarterly excess return of foreign bonds on the forward discount yields a

\footnotetext{
${ }^{10}$ Duffie and Sun (1990), Lynch (1996), Gabaix and Laibson (2002), and Peng and Xiong (2005) have all developed models where investors make infrequent portfolio decisions because of a fixed cost of information collection and decision making.

${ }^{11}$ The paper is also related to a growing literature in macroeconomics based on rational inattention, in particular in the context of price setting by firms and consumption decisions by households. Examples are Sims (1998, 2003), Mackowiak and Wiederholt (2005), Mankiw and Reis (2002), Moscarini (2004), Reis (2004a,b) and Carroll (2003).
} 
large negative coefficient of -1.74 . Third, we find that average expectational errors about future exchange rates are predictable by the forward discount and in the same direction as in the data. Fourth, even though excess returns are predictable in the model, this is overshadowed by uncertainty. The $R^{2}$ of the excess return regression is very low, again consistent with the data. Finally, the model implies delayed overshooting in response to interest rate shocks. Eichenbaum and Evans (1995) first documented that after a rise in the interest rate a currency continues to appreciate for about another year before it starts to depreciate. This is another puzzle in international finance that standard models cannot explain. ${ }^{12}$

The remainder of the paper is organized as follows. In Section 2, we provide some basic intuition for how inattention can lead to the predictability of excess returns. In section 3 we present the foreign exchange model and the solution procedure. In section 4 , we calibrate the model to the data and we show that it can explain the forward discount and delayed overshooting puzzles. We discuss in detail the various aspects leading to these results. Section 5 concludes.

\section{How Does Inattention Explain Predictability?}

In this section we provide some intuition for the impact of inattention on excess return predictability. Without a formal model, the explanation has been suggested earlier by Froot and Thaler (1990) and Lyons (2001). Consider an increase in the domestic interest rate. This causes an increased demand for domestic bonds and an appreciation of the domestic currency. If the expected excess return were zero, the exchange rate would subsequently be expected to depreciate since $E_{t}\left(s_{t+1}-s_{t}\right)=$ $i_{t}-i_{t}^{*}$. But if investors are slow to respond to the news of a higher domestic interest rate, there will be a continued reallocation of portfolios towards domestic bonds after the shock. In that case the initial appreciation is smaller and the currency will continue to appreciate subsequent to the shock. This leads to a negative relationship between the forward discount and the subsequent change in the exchange rate, as first documented by Fama (1984). It implies a coefficient of less than -1 of a regression of the excess return on the forward discount. It is also consistent with evidence of delayed overshooting.

\footnotetext{
${ }^{12}$ Gourinchas and Tornell (2004) explain both predictability and delayed overshooting with distorted beliefs on the interest rate process.
} 
The impact of inattention on the equilibrium asset price is driven by the dynamic response of the portfolio differential $b_{t}^{I}-b_{t}^{A}$, where $b_{t}^{A}$ and $b_{t}^{I}$ are the fraction invested in Foreign bonds by attentive and inattentive agents. If for example a fraction $\lambda$ of financial wealth is held by attentives, the total fraction invested in foreign bonds is

$$
\lambda b_{t}^{A}+(1-\lambda) b_{t}^{I}=b_{t}^{A}+(1-\lambda)\left(b_{t}^{I}-b_{t}^{A}\right)
$$

The second term on the right-hand side of (1) depends on the portfolio differential. The role of inattention is captured by this additional demand term. It tells us how the demand function for foreign bonds shifts due to inattention. Without modeling the behavior of either attentives or inattentives, to which we turn in the next section, assume for now that the portfolio of inattentives responds more slowly to new information than the portfolio of attentives.

Consider again a rise in the domestic interest rate. This causes $b_{t}^{A}$ to fall because attentives shift their portfolio towards domestic bonds. But because inattentives are slow to respond, the fraction invested in foreign bonds by inattentives will rise relative to that of attentives. This amounts to an increase in demand for foreign bonds due to inattention, captured by the last term in (1). Over time this gap will close as inattentives catch up. Therefore, investors expect the demand for foreign bonds to fall over time. This dynamic effect is of key importance to excess return predictability and is related to the intuition by Froot and Thaler (1990) and Lyons (2001). An expected decline in demand for foreign bonds associated with the gap $b_{t}^{I}-b_{t}^{A}$ leads by itself to an expected appreciation of the domestic currency and therefore to a negative relationship between the forward discount and the subsequent change in the exchange rate. When this effect is strong enough it can more than offset the positive relationship between the forward discount and the subsequent change in the exchange rate that is due to the behavior of attentive agents in isolation. ${ }^{13}$

Inattention only matters to the extent that shocks affect relative asset supplies. In the example above, if interest rate shocks have no effect on relative asset supplies, then the portfolio of attentives would not change in equilibrium. In that case

\footnotetext{
${ }^{13}$ There is also a level effect on the exchange rate due to the increase in the expected present value of demand for foreign bonds associated with the inattention gap $b_{t}^{I}-b_{t}^{A}$. However, it has no effect on excess return predictability since $s_{t+1}-s_{t}$ is unaffected by a permanent demand shock that leads to a permanent change in the exchange rate.
} 
it makes no difference if some investors are inattentive. Relative asset supplies change naturally though in response to interest rate shocks since it affects the exchange rate and therefore relative asset supplies if bond supplies are fixed in local currencies.

\section{$3 \quad$ A Model of Rational Inattention}

In this section we present a model of rational inattention applied to the foreign exchange market. We first describe the basic structure of the model and then discuss the solution method. Some technical details are covered in the Appendix, with a Technical Appendix available on request providing full technical detail.

\subsection{Model's Description}

\subsubsection{Basic Setup}

We will describe a two-country dynamic general equilibrium model. Our overall approach is to keep the model as simple as possible while retaining the key ingredients needed to highlight the role of rational inattention. There is a single good and purchasing power parity: $p_{t}=s_{t}+p_{t}^{*}$, where $p_{t}$ is the log-price level of the good in the Home country and $s_{t}$ the log of the nominal exchange rate. Foreign country variables are indicated with a star. There are three assets: one-period nominal bonds in both currencies issued by the respective governments and a riskfree technology with real return $\bar{r}^{14}$ Bonds are in fixed supply in the respective currencies. ${ }^{15}$ There are overlapping generations of investors who each live $T+1$ periods and derive utility from end of life wealth. Each period a total of $n$ new investors are born, endowed with one unit of the good that can be invested in the three assets.

\footnotetext{
${ }^{14}$ This is necessary to tie down the real interest rate since the model does not contain saving and investment decisions. Otherwise equality between savings and investment would tie down the real interest rate.

${ }^{15}$ Bonds are issued by the respective governments. One can think of governments owning claims on the riskfree technology whose proceeds are sufficient to pay the interest on the debt. The remainder is thrown in the water or spent on public goods that have no effect on the marginal utility from private consumption.
} 
We will first describe the monetary policy rules adopted by central banks, then the modeling of inattention and optimal portfolio choice, and finally asset market clearing.

\subsubsection{Monetary Policy}

Central banks adopt the following monetary policies. The interest rate rule in the Foreign country is

$$
i_{t}^{*}=\psi\left(p_{t}^{*}-\bar{p}_{t}^{*}\right)-u_{t}
$$

where

$$
u_{t}=\rho u_{t-1}+\varepsilon_{t}^{u} \quad \varepsilon_{t}^{u} \sim N\left(0, \sigma_{u}^{2}\right)
$$

and $\bar{p}_{t}^{*}$ is the target log price level, which we will simply set at zero. With this Wicksellian policy rule the central bank cares about the price level. ${ }^{16}$ It can also be derived from a standard money market equilibrium equation, where money demand depends negatively on the interest rate with coefficient $1 / \psi$ and $u_{t}$ represents money demand and supply shocks. It is assumed that $u_{t}$ follows an AR process with normally distributed innovations.

As a simplifying assumption we assume that $\psi \rightarrow \infty$ for the Home country, so that the central bank in the Home country commits to a constant price level. This implies zero inflation, so that $i_{t}=\bar{r}$. Without loss of generality we assume that the constant domestic price level is 1 , so that $p_{t}=0$ and $p_{t}^{*}=-s_{t}$. The Foreign interest rate rule can therefore also be written as

$$
i_{t}^{*}=-\psi s_{t}-u_{t}
$$

These assumptions imply that there are in essence only two assets, one with a risk-free real return $\bar{r}$ and one with a stochastic real return. The latter is Foreign bonds, which has a real return of $s_{t+1}-s_{t}+i_{t}^{*}$. This setup leads to much simpler portfolios than we would get under symmetric monetary policy rules, in which case the real return on Home and Foreign bonds would both be stochastic.

\subsubsection{Modeling Inattention}

Three elements make it difficult to solve a general dynamic model with rational inattention. First, investors need to make decisions about the frequency of infor-

\footnotetext{
${ }^{16}$ See Woodford (2003) for a discussion.
} 
mation processing. ${ }^{17}$ Second, portfolio decisions are much more complicated when expected returns are time varying. Third, the exchange rate is endogenous.

For tractability reasons, we simplify decisions about the frequency of information processing. Since investors live $T+1$ periods, they can make a maximum of $T$ portfolio decisions. We assume that when investors are born they have the choice to either make one portfolio decision for the next $T$ periods or actively manage their portfolio each period. ${ }^{18}$ Active portfolio management leads to higher expected portfolio returns, but it involves a per-period information processing cost of $\tau_{i}$ as a fraction of investor $i$ 's wealth. Dependent on the information processing cost they face, some investors (a fraction $f$ ) will choose to actively manage their portfolio. We call them "attentives". The remaining fraction $1-f$ of investors will make only one portfolio decision. We call them "inattentives". At any point in time there will be $T$ generations of attentive and inattentive investors.

It is useful to define the cost of being inattentive $\tau(f)$ such that the expected utility of an investor is the same under both investment strategies; this cost depends obviously on the number of attentive investors in the market. Investor $i$ will decide to be attentive if $\tau_{i}<\tau(f)$ and inattentive when $\tau_{i}>\tau(f)$. In equilibrium, $f$ is determined by the distribution of $\tau_{i}$ over investors. If $f(\tau)$ is a differentiable cumulative distribution function of this cost, the equilibrium level $f^{*}$ is such that $f\left(\tau\left(f^{*}\right)\right)=f^{*}$. This determines the threshold information processing cost $\tau^{*}=$ $\tau\left(f^{*}\right)$. Investors with a lower information processing cost will be attentive, while others rationally choose to be inattentive.

Attentive investors in the model make multi-period portfolio decisions. With time-varying expected returns the portfolio choice problem will be significantly

\footnotetext{
${ }^{17}$ In some models of rational inattention, based on Information Theory, investors also choose what type of information to collect. See for example Sims $(1998,2003)$ and Mackowiak and Wiederholt (2005). In these models, where investors have a limited capacity to process information, investors process a limited amount of information each period. However, Moscarini (2004) has shown that when the capacity can be increased at a cost, it is optimal for investors to process information infrequently rather than each period.

${ }^{18}$ This is a simplification relative to a more general setup where investors have infinite lives and need to decide on the frequency of information processing. Such a setup is unfortunately intractable when combined with the endogeneity of asset returns. The few papers in finance where the frequency of transactions is endogenous due to information processing costs, such as Duffie and Sun (1990) and Gabaix and Laibson (2002), assume exogenous asset returns that are uncorrelated over time.
} 
more complicated due to a hedge against changes in future expected returns. Solutions to multi-period portfolio problems with time-varying expected returns have only been derived in the literature for exogenous returns. ${ }^{19}$ For the purpose of solving the equilibrium exchange rate we approximate the portfolio of attentive investors as the optimal portfolio of one-period investors. This omits the hedge term. Once we have solved for the equilibrium exchange rate we also compute the precise portfolio. That problem is tractable since we have already solved for the exchange rate and therefore the stochastic process of the return on Foreign bonds is given. We find that the hedge term is non-zero and time varying, but swamped by the regular myopic portfolio term that depends on expected returns and risk. The correlation between the two portfolios is larger than 0.9999. The approximation is therefore very accurate.

Once we have solved for the equilibrium exchange rate for a given $f$, we can compute $\tau(f)$ by comparing expected utility under both portfolio strategies. In doing so we use the precise solution to the $T$-period investment problem under active portfolio management since the equilibrium exchange rate, and therefore Foreign bond return process, has already been computed.

\subsubsection{Portfolio Choice}

We now turn to the optimal portfolios of attentives and inattentives. Since PPP holds, Foreign and Home investors face the same real returns and therefore choose the same portfolio. We assume constant relative risk-aversion preferences over end-of-life consumption, with a rate of relative risk-aversion of $\gamma$. This runs into the well-known problem though that for any reasonable rate of risk aversion the portfolio of attentive investors becomes extremely sensitive to small changes in expected excess returns. A one percent increase in the expected excess return can cause investors to easily shift from investing nothing to investing their entire portfolio in an asset. A natural way to reduce the resulting excessive portfolio volatility is to introduce parameter uncertainty or transaction costs. But both of these devices would significantly complicate the model. ${ }^{20}$

\footnotetext{
${ }^{19}$ See Campbell and Viceira (1999) and references therein.

${ }^{20}$ For example, transaction costs would lead to non-linear portfolio rules with zones of inaction for expected excess returns inside some boundaries (s-S rules). See Baldwin (1990) in the context of the foreign exchange market.
} 
We adopt a more tractable solution by assuming that it is costly for investors to deviate too far from a certain benchmark portfolio. To be precise, we assume that a deviation from a benchmark portfolio leads to a cost that reduces the investment return by $0.5 \gamma \sigma_{A}^{2} \phi\left(b_{t}-b\right)^{2}$, where $b_{t}$ is fraction invested in Foreign bonds, $b$ is the benchmark fraction invested in Foreign bonds, $\sigma_{A}^{2}$ is the conditional variance of next period's exchange rate, and $\phi \geq 0$.

Approximating the portfolio choice of attentive investors as that of one-period horizon investors, we need to maximize $E_{t} W_{t+1}^{1-\gamma} /(1-\gamma)$, where next period's financial wealth is equal to

$$
\begin{aligned}
& W_{t+1}=R_{t+1}^{p} \eta_{t} \\
& \eta_{t}=e^{-0.5 \gamma \sigma_{A}^{2} \phi\left(b_{t}^{A}-b\right)^{2}}
\end{aligned}
$$

Here $b_{t}^{A}$ is the fraction invested in Foreign bonds and the gross investment return $R_{t+1}^{p}$ is

$$
R_{t+1}^{p}=\left(1-b_{t}^{A}\right) e^{i_{t}}+b_{t}^{A} e^{s_{t+1}-s_{t}+i_{t}^{*}}
$$

In order to solve for optimal portfolios we approximate the first order condition by dropping terms that are higher than second order. ${ }^{21}$ In a continuous time framework these terms would drop naturally. In Appendix A.1 we show that this gives the familiar portfolio rule

$$
b_{t}^{A}=b^{A}+\frac{E_{t} q_{t+1}}{\gamma \sigma_{A}^{2}(1+\phi)}
$$

where $b^{A}$ is a constant, $q_{t+1}=s_{t+1}-s_{t}+i_{t}^{*}-i_{t}$ is the excess return on Foreign bonds and $\sigma_{A}^{2}=\operatorname{var}_{t}\left(q_{t+1}\right)$ its conditional variance. The benchmark portfolio adjustment cost therefore dampens the portfolio response to expected return changes by a factor $1 /(1+\phi)$.

Inattentives born at time $t$ maximize $E_{t} W_{t+T}^{1-\gamma} /(1-\gamma)$, where $W_{t+T}$ is end of life financial wealth that will be consumed. Since inattentives make only one portfolio decision when born, investing a fraction $b_{t}^{I}$ in Foreign bonds, end of life wealth is

$$
W_{t+T}=\prod_{j=1}^{T} R_{t+j}^{p} \eta_{t}
$$

\footnotetext{
${ }^{21}$ Engel and Matsumoto (2005) use the same approach to solve for optimal portfolios in a general equilibrium model with home bias.
} 


$$
\begin{aligned}
& R_{t+j}^{p}=\left(1-b_{t}^{I}\right) e^{i_{t+j-1}}+b_{t}^{I} e^{s_{t+j}-s_{t+j-1}+i_{t+j-1}^{*}} \\
& \eta_{t}=e^{-0.5 \gamma \sigma_{A}^{2} \phi\left(b_{t}^{I}-b\right)^{2}}
\end{aligned}
$$

Following again an approach that drops terms higher than second order from the first order condition, Appendix A.1 shows that the resulting optimal portfolio is

$$
b_{t}^{I}=b^{I}+\frac{E_{t} q_{t, t+T}}{\gamma \sigma_{I}^{2}+T \gamma \sigma_{A}^{2} \phi}
$$

where $b^{I}$ is a constant, $q_{t, t+T}=q_{t+1}+. .+q_{t+T}$ is the cumulative excess return on Foreign bonds from $t$ to $t+T$, and $\sigma_{I}^{2}$ is defined as

$$
\sigma_{I}^{2}=\left(1-\frac{1}{\gamma}\right) \operatorname{var}_{t}\left(q_{t, t+T}\right)+\frac{1}{\gamma} \sum_{j=1}^{T} \operatorname{var}_{t}\left(q_{t+j}\right)
$$

There is one final group of investors that we refer to as liquidity traders. These are modeled exogenously. In the noisy rational expectations literature in finance it is very common to introduce exogenous noise or liquidity traders since this noise prevents the asset price from revealing the aggregate of private information. Here we do not have private information, but the exogenous liquidity traders are introduced to disconnect the exchange rate from observed macroeconomic shocks. It is well known since Meese and Rogoff (1983) that observed macro fundamentals explain very little of exchange rate volatility for horizons up to 1 or 2 years. This is what Lyons (2001) has called the exchange rate determination puzzle. In the absence of shocks to liquidity trade the exchange rate would only be driven by interest rate shocks in the model, in clear violation of the empirical evidence. ${ }^{22}$ The other advantage of introducing liquidity shocks is to be consistent with the low $R^{2}$ of regressions of the excess return on the forward discount. While changes in exchange rates are predictable by the forward discount, the extent of this predictive power is very limited.

\footnotetext{
${ }^{22}$ Bacchetta and van Wincoop $(2004,2006)$ show that in the presence of heterogenous information small liquidity shocks can have a large effect on exchange rates movements, so that exchange rates are disconnected from macroeconomic fundamentals. The exogenous "noise" that is generated by liquidity supply shocks can also be modeled endogenously, without any implications for the results. See Bacchetta and van Wincoop (2006) in the context of the foreign exchange market.
} 
Liquidity traders invest $x_{t} \bar{W}$ in Foreign bonds at time $t$, where $\bar{W}$ is aggregate steady state financial wealth and $x_{t}$ follows an AR process with mean zero:

$$
x_{t}=\rho_{x} x_{t-1}+\varepsilon_{t}^{x} \quad \varepsilon_{t}^{x} \sim N\left(0, \sigma_{x}^{2}\right)
$$

\subsubsection{Market Clearing}

We finally need to discuss the Foreign bond market clearing condition. There is a fixed supply $B$ of Foreign bonds in the Foreign currency. In real terms it is $B e^{-p_{t}^{*}}=B e^{s t}$. On the demand side each of the $T$ generations of investors has a total of $n_{A}=f n$ attentive investors and $n_{I}=(1-f) n$ inattentive investors. Investors are born with an endowment of one, but their wealth accumulates over time. Let $W_{t-j, t}^{A}$ be the wealth at time $t$ of an attentive investor born at $t-j$ and similarly $W_{t-j, t}^{I}$ for an inattentive investor born at $t-j$. These are equal to the product of total returns over the past $j$ periods. The market clearing condition for Foreign bonds is then

$$
n_{A} \sum_{j=1}^{T} b_{t}^{A} W_{t-j+1, t}^{A}+n_{I} \sum_{j=1}^{T} b_{t-j+1}^{I} W_{t-j+1, t}^{I}+x_{t} \bar{W}=B e^{s_{t}}
$$

We will set the real interest rate $\bar{r}$ such that the steady state fraction invested in Foreign bonds by attentives and inattentives together is equal to the benchmark portfolio $b$. Then the steady state supply divided by steady state wealth must also be $b: B e^{\bar{s}} / \bar{W}=b$. Without loss of generality we will assume that the nominal supply $B$ is such that this holds for $\bar{s}=0$.

Several non-linear terms show up in the market clearing condition. Portfolio demand depends on the product of portfolio shares and wealth, with the latter being a function of past portfolio shares and returns. The supply is also a nonlinear function of the log-exchange rate. We linearize this budget constraint around the point where the exchange rate and asset returns are zero and portfolio shares are equal to $b$. After linearization we subtract steady state values on both sides of the market clearing condition and divide by steady state wealth $\bar{W}$. Details can be found in Appendix A.2 and the Technical Appendix. We will think of liquidity demand shocks as equivalent to exogenous supply shocks, so that the linearized net supply after dividing by steady state wealth is $b s_{t}-x_{t}$. 


\subsection{Solution Method}

Details of the solution method are discussed in Appendix A.2 and in the Technical Appendix. Here we describe the main elements.

\subsubsection{Equilibrium Exchange Rate}

First, consider a given fraction of attentives $f$. We conjecture the following equilibrium exchange rate equation:

$$
s_{t}=A(L) \varepsilon_{t}^{u}+B(L) \varepsilon_{t}^{x}
$$

where $A(L)$ and $B(L)$ are infinite lag polynomials. Conditional on this conjectured exchange rate equation we compute excess returns as well as their first and second moments that enter into the optimal portfolios. We then solve for the parameters of the polynomials by imposing the linearized bond market equilibrium condition.

Since this involves an infinite number of non-linear equations in the parameters, we use the fact that the parameters of both polynomials approach zero as the lag length goes to infinity. This is because both interest rate shocks and supply shocks die out over time. We therefore set the coefficients of both polynomials equal to zero after a long lag. The cutoff is chosen very long so that lengthening it further has a negligible impact on the results. With a cutoff at $L$ lags, we then need to solve $2 L+1$ non-linear equations: $L$ equations for the parameters of each polynomial plus one equation that sets the real interest rate $\bar{r}$ such that the steady state fraction invested in Foreign bonds is $b$.

\subsubsection{Threshold Information Processing Cost}

In principle, we should specify the distribution $f(\tau)$ of information processing costs across investors and then find the equilibrium $\tau$ and $f$. Here we will follow the dual approach: we first set $f$, find $\tau(f)$, and then infer the distribution that is consistent with this solution. Any distribution of information processing costs such that a fraction $f$ of investors have a cost less than $\tau(f)$ and a fraction $1-f$ has a cost larger than $\tau(f)$ is consistent with this equilibrium. The advantage of the dual approach is that we do not have to write down the entire distribution function of information processing costs, about which little is known. We can instead focus on the threshold information processing cost $\tau(f)$. 
For the two approaches to be equivalent, the fraction of investors who choose to be attentive should be constant over time. To this end we assume that an investor born at time $t$ needs to choose his portfolio strategy at time $t$ before observing the current state. The latter is assumed to be equal to its unconditional mean with all past innovations being zero.

Appendix A.3 describes how we solve for the threshold information processing costs $\tau(f)$ where the expected utility of an investor is equal under the two portfolio strategies. Here we only provide a brief summary. Consider an attentive investor born at date $t$, who makes investment decisions at all dates $t, . ., t+T-1$. We need to solve for the value function at date $t$. This is done by backward induction. The value function at $t+T$ is $V_{t+T}=W_{t+T}^{1-\gamma} /(1-\gamma)$. For an information processing cost of $\tau$ we make an educated guess that the value function at $t+j$ takes the form $V_{t+j}=(1-\tau)^{(1-\gamma)(T-j)} e^{v_{t+j}} W_{t+j}^{1-\gamma} /(1-\gamma)$, where $v_{t+j}$ is a function of the state of the world at $t+j$. We then solve for the function $v_{t+j}$ by backwards induction from the Bellman equation $V_{t+j}=\max _{b_{t+j}^{A}} E_{t+j} V_{t+j+1}$. The maximization over the optimal portfolio at $t+j$ yields the myopic portfolio (8) plus a term that depends on the covariance between $v_{t+j+1}$ and the excess return $q_{t+j+1}$. We continue to iterate backwards to time $t$.

The state space at $t+j$ consists of $2 j$ innovations: $\left(\epsilon_{t+1}^{u}, . ., \epsilon_{t+j}^{u}, \epsilon_{t+1}^{x}, . ., \epsilon_{t+j}^{x}\right)$. When computing next period's expected value function we need to discretize the state space. We allow each innovation to take on $N$ different values, while preserving the mean and variance of the distributions. This means that the state space at $t+j$ can take on $N^{2 j}$ possible values. This quickly gets very large when we increase $N$. We set $N=3$, but we find virtually identical results for $N=4$. We use the same discrete distribution to compute the optimal portfolio and value function for inattentives.

\subsubsection{Multiple Equilibria}

Multiple equilibria could arise in the model and a detailed discussion is given in the Technical Appendix. More precisely, for a given fraction $f$ of attentive investors there can be multiple solutions to the equilibrium exchange rate equation. We show that there is either one equilibrium or three equilibria. However, the possibility of three equilibria has nothing to do with inattention and it also occurs when there 
are only attentive investors. Multiple equilibria arise as a result of the endogeneity of the conditional variance of the exchange rate. ${ }^{23}$ A higher conditional variance of next period's exchange rate leads to a bigger impact of supply shocks on the exchange rate through the risk premium. This can make the higher conditional variance self-fulfilling. We find that three equilibria only arise for an intermediate range of the standard deviation $\sigma_{x}$ of liquidity supply shocks. Below we set $\sigma_{x}$ to match the observed unconditional exchange rate volatility. Even though for a given $\sigma_{x}$ there may be multiple equilibria, there is only one $\sigma_{x}$ and one corresponding equilibrium that matches a given level of the unconditional variance of the exchange rate. $^{24}$

\section{Numerical Results}

We now calibrate the model and examine its quantitative implications for excess return predictability.

\subsection{Parameterization}

The parameters of the model are chosen as follows. A period is set equal to one quarter. The parameter $\psi$ corresponds to the inverse of the derivative of money demand with respect to the interest rate. Engel and West (2005) discuss the existing evidence on this parameter, with estimates of $1 / \psi$ for quarterly data ranging from 29 to 60 . We set $\psi=0.03$, corresponding to $1 / \psi=33$. The $\mathrm{AR}$ process for $u_{t}$ is estimated as follows. From (2) we have $-u_{t}=i_{t}^{*}-\psi\left(p_{t}^{*}-\bar{p}_{t}^{*}\right)$. We compute $u_{t}$ for the countries and sample period corresponding to the excess return regression reported in Table 1 . The trend price level $\bar{p}_{t}^{*}$ is approximated with an $\operatorname{HP}(1600)$ filter. We set $\rho_{u}$ and $\sigma_{u}$ equal to the average across the countries of the estimated process. This yields $\rho_{u}=0.957$ and $\sigma_{u}=0.00248$.

The process for the supply $x_{t}$ cannot be observed directly. We set the standard deviation $\sigma_{x}$ of the innovation to this AR process such that the implied exchange

\footnotetext{
${ }^{23}$ See McCafferty and Driskill (1980) for a discussion of this source of multiplicity.

${ }^{24}$ Multiple solutions to the equilibrium exchange rate equation for a given $f$ may also lead to multiple solutions to $f$ for a given distribution function of information processing costs. The Technical Appendix discusses this in further detail.
} 
rate volatility in the model matches that in the data. To be precise, $\sigma_{x}$ is set such that the standard deviation of $s_{t+1}-s_{t}$ in the model is equal to the GDP weighted average standard deviation of the one quarter change in the log exchange rate for the five currencies and time period of the excess return regression reported in Table 1. The average standard deviation is 0.057 . We have little information about the persistence $\rho_{x}$ of supply shocks, which is set at 0.5 .

The rate of relative risk aversion is set at 5 , which is probably not too far from the average of a broad range of empirical estimates of this parameter. We set $b=0.5$, corresponding to a two-country setup with half of the assets supplied by the US and the other half by the rest of the world. This leaves three key parameters: $f, T$ and $\phi$. We will vary these parameters over a wide range to evaluate their role. In the benchmark parameterization we set $f=0.05, T=5$ and $\phi=10$. While the parameter $f$ is endogenous for a given distribution function of information processing, our dual approach focuses on the threshold information processing cost $\tau(f)$.

\subsection{Results for Benchmark Parameterization}

The first column in Table 2 reports results for the benchmark parameterization. The results are consistent with empirical evidence along various dimensions. First, a regression of the excess return of Foreign bonds on the forward discount yields a coefficient of -1.74 , not far from the bias seen in the data reported in Table 1 . If instead all investors were attentive, the coefficient would be only -0.29 . We refer to the difference of -1.45 as the bias due to inattention (second row). Second, as shown in the third row of Table 2, the model implies a large negative coefficient in a regression of the average expectational error on the forward premium. Third, the annualized threshold information processing cost $\tau(f)$ that is consistent with the equilibrium is only $2.38 \%$. It is not implausible that $95 \%$ of investors face an information processing cost of at least $2.38 \%$. For example, hedge funds, who come closest to being fully attentive, charge more than that on an annual basis through various fees. Fourth (not reported in Table 2), the $R^{2}$ of the excess return regression is only 0.038 , even a bit lower than in the data. ${ }^{25}$

\footnotetext{
${ }^{25}$ Related to this, $90 \%$ of the variance of quarterly exchange rate changes is associated with liquidity supply shocks, which is consistent with the evidence of a disconnect between exchange
} 
Finally, the model implies delayed overshooting. This is illustrated in Figure 1 , which shows impulse response of the exchange rate in response to a one standard deviation decrease in the Foreign interest rate. The lower Foreign interest rate causes an immediate appreciation of the Home currency, followed by a continued appreciation in the next several quarters, after which is starts to gradually depreciate. The delayed overshooting is closely related to the excess return predictability. It implies a negative relationship between the forward discount and $s_{t+1}-s_{t}$, which by itself leads to a coefficient of less than -1 in a regression of the excess return on the forward discount. In contrast, Figure 1 shows that there is no delayed overshooting in the absence of inattentives $(f=1)$. In that case the exchange rate immediately starts to depreciate subsequent to the shock.

Figure 2 provides some intuition behind the excess return predictability for the benchmark parameterization. It reports impulse responses to one standard deviation interest rate and supply shocks. Panels A and B report results for interest rate shocks and panels $\mathrm{C}$ and $\mathrm{D}$ for supply shocks. It is immediately evident from panels $\mathrm{A}$ and $\mathrm{C}$ that both interest rate and supply shocks lead to a negative relationship between the excess return and the forward discount.

The other two panels show the response of portfolios of attentives and inattentives to the shocks. This provides the necessary intuition behind the negative relationship between the excess return and the forward discount. First consider a drop in the Foreign interest rate. Attentive investors reduce their holdings of Foreign bonds much more quickly than inattentives, as illustrated in panel B. In the subsequent quarters inattentives continue to sell Foreign bonds, while attentives gradually increase their holdings of Foreign bonds. The role of inattention is captured by the decline over time in the relative holdings of Foreign bonds by inattentives, which implies a continued appreciation over time of the Home currency. This explains the delayed overshooting illustrated in Figure 1. It also explains the negative relationship between the excess return and the forward discount illustrated in panel A of Figure 2. The lower Foreign interest rate raises the forward discount. The excess return on Foreign bonds is reduced both by the lower interest rate on Foreign bonds and the continued appreciation of the domestic currency.

Panels C and D of Figure 2 illustrate the dynamic response to a one standard rates and observed macro fundamentals. 
deviation increase in $x_{t}$, which is equivalent to a lower supply of Foreign bonds. It leads to an appreciation of the Foreign currency and therefore lower prices in the Foreign country. This leads to more expansionary Foreign monetary policy (lower interest rate) that increases the forward discount $f d_{t}$ by a little bit as shown in panel $\mathrm{C}$. Panel $\mathrm{C}$ shows that at the same time the excess return on Foreign bonds drops. The excess return would also decrease in the absence of inattentives due to a lower risk premium on the smaller supply of Foreign bonds. ${ }^{26}$ But $q_{t+1}$ drops much more due to inattention. Since inattentives are slow to respond to a lower expected return on Foreign bonds, their relative holdings of Foreign bonds is temporarily higher than that of attentives, as illustrated in panel D. The subsequent drop in the relative holdings of Foreign bonds by inattentives by itself implies a gradual appreciation of the Home currency that contributes to the lower excess return on Foreign bonds.

In the literature, the predictability of excess returns is often written as the sum of a component due to time-varying risk premia and predictable expectational errors. More generally, explanations for predictability based on time-varying risk premia and predictable expectational errors are considered as mutually exclusive. This is not the case here. On the one hand there are predictable expectational errors in the model due to rational inattention. On the other hand, from the perspective of attentive agents one could regard the excess return predictability as entirely the result of time-varying risk premia. ${ }^{27}$ If $r p_{t}$ is the risk premium of attentives, we have $E_{t} q_{t+1}=r p_{t}$, where $E_{t}$ is the expectation of attentives. The excess return is then the sum of the risk premium and the expectational error of attentives: $q_{t+1}=r p_{t}+\left(q_{t+1}-E_{t} q_{t+1}\right)$. Since expectational errors by attentives are not predictable, the predictability of the excess return is entirely associated with $r p_{t}$. However, the driving force for excess return predictability in the model is rational inattention: it is responsible for both the time-varying risk premia of attentives and predictable expectational errors.

\footnotetext{
${ }^{26}$ In the absence of inattentives, this is the mechanism leading to a negative relationship between the forward discount and excess return in McCallum (1994).

${ }^{27}$ Since the portfolio of inattentives does not satisfy a standard arbitrage condition at all times, it is somewhat arbitrary to define what their risk premium is.
} 


\subsection{Sensitivity Analysis}

The last five columns of Table 2 conduct sensitivity analysis for the two key parameters $f$ and $T$. Below we will also briefly comment on the parameter $\phi$. When we change $f$ we implicitly also change the cumulative distribution function of information processing costs to be consistent with the higher or lower fraction of attentives. The same is also the case when we change $T$ or $\phi$ for a given fraction of attentives $f$. In each case we report the threshold information processing cost that is consistent with an equilibrium for the new parameterization.

Sensitivity analysis can be conducted in two different ways. The most standard way is reported in panel A. We only change one parameter $(f$ or $T)$. This answers the question of how the moments would change if investors become more or less attentive. In panel $\mathrm{B}$ we simultaneously change $\sigma_{x}$ in order to match the observed unconditional standard deviation of $s_{t+1}-s_{t}$ observed in the data. There the goal is to ask how well the model can match the data for different values of $f$ and $T$. Panels A and B therefore address different questions. ${ }^{28}$

Panel A shows that excess return predictability is very sensitive to the degree of attentiveness, measured either by the fraction $f$ of attentives or the frequency $T$ of trading by inattentives. The predictability bias coefficient becomes -6.5 in the absence of attentives $(f=0)$ and drops to -0.57 when $10 \%$ of wealth is held by attentives $(f=0.1)$. Similarly, the bias is -6.1 when inattentives hold their portfolio constant for 8 periods $(T=8)$ but is only -0.55 when they hold their portfolio constant for only 3 periods.

Two factors play a role here. First, it is natural that larger profit opportunities will remain unexploited when investors are less attentive. Second, attentive investors are less willing to exploit expected profit opportunities when there is a lot of risk. The less attentive investors are (either lower $f$ or higher $T$ ), the more volatile the exchange rate and therefore the more uncertainty. The reason is that the exchange rate is much more responsive to liquidity supply shocks when there are fewer attentive investors to "absorb" these shocks. As shown in panel A, both the unconditional and conditional volatility rise significantly for $f=0$ or $T=8$.

\footnotetext{
${ }^{28}$ Multiple equilibria do not arise in either of these panels. For any given level of exchange rate volatility matched by varying $\sigma_{x}$ (panel B) there is only a single equilibrium. Multiple equilibria could arise in panel $\mathrm{A}$, but this only happens for very small changes in $f$ away from the benchmark (which we do not report).
} 
Panel A also suggests that it is unlikely that all investors, or even $10 \%$ of investors, become attentive due to a drop in information processing costs. For $f=1$ we find that the annual information processing cost $\tau$ is only $0.02 \%$. This can therefore only be an equilibrium if all investors have an information processing cost of less than $0.02 \%$. Even $f=0.1$ seems unlikely since it implies that $10 \%$ of investors must have an annual information processing cost of less than $0.63 \%$. The reason for this result is that when many investors (or even $10 \%$ of investors) become attentive, most profit opportunities will already be exploited and therefore the gain from being attentive is very low.

The predictability bias coefficient is much less sensitive to $f$ and $T$ in panel $\mathrm{B}$, where $\sigma_{x}$ is adjusted to match the unconditional exchange rate volatility in the data. The reason for this is as follows. Even though by itself a larger number of attentives would reduce exchange rate volatility, as illustrated in panel A, we now increase $\sigma_{x}$ at the same time to keep the unconditional variance of the exchange rate unchanged. When the unconditional variance is unchanged with an increase in $f$, the conditional variance becomes larger because changes in exchange rates are less predictable when there are more attentives. The higher conditional variance implies more uncertainty about future returns, making it less attractive for attentives to exploit expected profit opportunities. Therefore predictability drops only slowly if we increase $f$.

Even for $f=1$ the predictability bias remains large, at -1.54 . However, in this case the quarterly standard deviation $\sigma_{x}$ of liquidity supply shocks necessary to match observed exchange rate volatility is $20.56 \%$ of aggregate financial wealth (for $f=0$ it is only $1.94 \%$ ). Even though we cannot measure these supply shocks directly, this appears implausibly large. It is not surprising that with such enormous supply shocks one can obtain very large time varying risk premia. Moreover, expectational errors are not predictable in this case, in contrast to the data. Finally, the threshold information processing cost is only $0.96 \%$. Since most investors face a larger cost of information processing, an equilibrium where all investors are attentive seems improbable.

Table 2 does not report any sensitivity analysis with respect to $\phi$. The main point that we like to emphasize about this parameter is that portfolios become excessively volatile when $\phi$ is low. For the benchmark where $\phi=10$ the standard deviation of the quarterly portfolio change of attentives is $51 \%$, which already 
appears large. However, if $\phi=0$ and $\sigma_{x}$ is set to match observed exchange rate volatility, the standard deviation of the quarterly portfolio change of attentives becomes $480 \%$ ! Even though we do not have good data to compare this to, for example from hedge funds, this is implausible. ${ }^{29}$ When we set $\phi=20$, the standard deviation of the quarterly change of the portfolio of attentives goes down to $27 \%$. The overall predictability bias is -1.81 in that case.

\section{Conclusion}

Understanding why uncovered interest parity does not hold empirically is important for policy and for modeling decisions. In this paper we explore a new explanation, based on rational inattention whereby investors make infrequent portfolio decisions due to a cost of acquiring and processing information. We show that a calibrated model can match the evidence on the forward discount puzzle. It also produces delayed overshooting and predictable expectational errors, two important features of the empirical evidence on exchange rates.

It is useful to emphasize again some key elements regarding the investors in the model. First, investors are perfectly rational regarding their portfolio choice and frequency of portfolio decisions. Second, attentive investors do not necessarily unravel the impact of inattentive investors on excess return predictability. This is because attentive investors are risk averse and the conditional variance of future exchange rates is large. Attentives therefore only make limited bets on excess returns in their portfolio choice. Finally, we have shown that for reasonable information processing costs it can be optimal for only a small fraction of investors to be attentive.

So far, the literature has made a stark contrast between explanations of the forward discount puzzle based on the risk premium and explanations based on expectational errors. Our model sheds new light on this debate. First, we show that the two types of explanations are not necessarily related to a debate around the assumption of pure rationality, since predictable expectational errors may exist when investors are strictly rational but face information processing costs. Second, our analysis shows that there is no clear-cut distinction between risk premium

\footnotetext{
${ }^{29}$ Not surprisingly, this also leads to a very large annual welfare gain from attention, leading to a threshold information processing cost of $16.2 \%$
} 
and expectational errors when investors are heterogeneous. More specifically, the excess return is equal to the risk premium of attentive investors, which in turn is determined by expectational errors by inattentive investors.

We have kept the model as simple as possible in order to both keep it tractable and highlight the role of rational inattention. A natural direction for future work is to integrate the features that we have described here into richer models. In particular, we abstracted from saving and investment decisions and nominal rigidities. One could also consider richer monetary policy reaction functions. The introduction of bonds of different maturities could shed light on rejections of the expectations hypothesis and the documented closer fit of uncovered interest rate parity over long horizons for long term bonds. Ultimately one would also like to investigate the implications of such models for optimal monetary policy and the choice of exchange rate regime. 


\section{A Appendix}

In this Appendix, we sketch the main steps to derive the portfolios of attentive and inattentive investors and to solve the model. More details can be found in a Technical Appendix available upon request.

\section{A.1 Optimal Portfolios}

We first describe how we derive the optimal of portfolio of inattentive investors (12). Inattentives born at time $t$ maximize $E_{t} W_{t+T}^{1-\gamma} /(1-\gamma)$ subject to (9)-(11). The first order condition for the portfolio $b_{t}^{I}$ is then

$$
E_{t} R_{t+T}^{-\gamma}\left[\sum_{j=1}^{T} \frac{\partial R_{t+j}^{p}}{\partial b_{t}^{I}} \frac{R_{t+T}}{R_{t+j}^{p}}-R_{t+T} T \gamma \sigma_{A}^{2} \phi\left(b_{t}^{I}-b\right)\right]=0
$$

where

$$
R_{t+T}=\prod_{j=1}^{T} R_{t+j}^{p}
$$

In solving for the optimal portfolio we drop terms that naturally drop out in continuous time anyway. These are third and higher order terms. Expected returns and variances are second order terms (depend on $d t$ in continuous finance). Stochastic returns are first order, while deterministic returns are second order (like expected returns). We need to take second order approximations of first order variables and first order approximations of second order variables. This corresponds to dropping terms higher than second order.

We start by taking a second order approximation of log-portfolio returns around zero Home and Foreign bond returns. This yields $\ln R_{t+j}^{p}=i_{t+j-1}+b_{t}^{I} q_{t+j}+h_{t}$, where $h_{t}=0.5 b_{t}^{I}\left(1-b_{t}^{I}\right) \sigma_{A}^{2}$ is a second order term. Similarly $\ln R_{t+T}=i_{t, t+T}+$ $b_{t}^{I} q_{t, t+T}+T h_{t}$, where $i_{t, t+T}=i_{t}+. .+i_{t+T-1}$.

We can then rewrite (17) as:

$$
\begin{aligned}
& \sum_{j=1}^{T} E_{t} e^{(1-\gamma) b_{t}^{I} q_{t, t+T}-b_{t}^{I} q_{t+j}}=\sum_{j=1}^{T} E_{t} e^{(1-\gamma) b_{t}^{I} q_{t, t+T}+\left(1-b_{t}^{I}\right) q_{t+j}} \\
& -T \gamma \sigma_{A}^{2} \phi\left(b_{t}^{I}-b\right) E_{t} e^{(1-\gamma) b_{t}^{I} q_{t, t+T}+h_{t}}
\end{aligned}
$$


In equilibrium log excess returns will be normally distributed, so that the expectations are easy to compute:

$$
\begin{aligned}
& \sum_{j=1}^{T} e^{b_{t}^{I} E_{t}\left((1-\gamma) q_{t, t+T}-q_{t+j}\right)+0.5\left(b_{t}^{I}\right)^{2} \operatorname{var}_{t}\left((1-\gamma) q_{t, t+T}-q_{t+j}\right)}= \\
& \sum_{j=1}^{T} e^{(1-\gamma) b_{t}^{I} E_{t} q_{t, t+T}+\left(1-b_{t}^{I}\right) E_{t} q_{t+j}+0.5 v a r\left((1-\gamma) b_{t}^{I} q_{t, t+T}+\left(1-b_{t}^{I}\right) q_{t+j}\right)} \\
& -T \gamma \sigma_{A}^{2} \phi\left(b_{t}^{I}-b\right) E_{t} e^{(1-\gamma) b_{t}^{I} E_{t} q_{t, t+T}+0.5(1-\gamma)^{2}\left(b_{t}^{I}\right)^{2} \operatorname{var}_{t}\left(q_{t, t+T}\right)+h_{t}}
\end{aligned}
$$

Since the terms in the exponentials are second order, we need to only take a first order approximation around these terms being zero (replacing $e^{x}$ with $1+x$ ). Doing so, and dropping a third order term that multiplies $b_{t}^{I}-b$ and second order terms, yields

$$
\begin{aligned}
& -b_{t}^{I} E_{t} q_{t, t+T}+\sum_{j=1}^{T} 0.5\left(b_{t}^{I}\right)^{2}\left(\operatorname{var}_{t}\left(q_{t+j}\right)-2(1-\gamma) \operatorname{cov}\left(q_{t+j}, q_{t, t+T}\right)\right)= \\
& \left(1-b_{t}^{I}\right) E_{t} q_{t, t+T}+0.5\left(1-b_{t}^{I}\right)^{2} \sum_{j=1}^{T} \operatorname{var}_{t}\left(q_{t+j}\right) \\
& +(1-\gamma) b_{t}^{I}\left(1-b_{t}^{I}\right) \sum_{j=1}^{T} \operatorname{cov}\left(q_{t+j}, q_{t, t+T}\right)-T \gamma \sigma_{A}^{2} \phi\left(b_{t}^{I}-b\right)
\end{aligned}
$$

It is straightforward to derive (12) from (21), where:

$$
b^{I}=\frac{0.5 \sum_{j=1}^{T} \operatorname{var}_{t}\left(q_{t+j}\right)+b T \gamma \sigma_{A}^{2} \phi}{\gamma \sigma_{I}^{2}+T \gamma \sigma_{A}^{2} \phi}
$$

An alternative way of deriving the same portfolio is to take a second order approximation of the first order condition around zero returns, then replace returns with second order approximations and then take expectations (dropping higher than second order terms).

The optimal portfolio for attentives can be derived following the same procedure as above. This corresponds to setting $T=1$ and $\sigma_{I}^{2}=\sigma_{A}^{2}$ in the portfolio of inattentives, which gives (8) with

$$
b^{A}=\frac{0.5+\gamma \phi b}{\gamma(1+\phi)}
$$




\section{A.2 Solving the Equilibrium Exchange Rate}

First we linearize the market equilibrium condition. The algebraic details can be found in the Technical Appendix. After subtracting the steady state from both the demand and supply side of the market equilibrium equation we find

$$
\begin{aligned}
& f \frac{E_{t} \tilde{q}_{t+1}}{\gamma \sigma_{A}^{2}(1+\phi)}+(1-f) \frac{1}{T} \sum_{j=1}^{T} \frac{E_{t-j+1} \tilde{q}_{t-j+1, t-j+1+T}}{\gamma \sigma_{I}^{2}+T \gamma \sigma_{A}^{2} \phi}+ \\
& \frac{1}{T} \sum_{j=1}^{T-1}(T-j) b^{2} \tilde{q}_{t-j+1}+w x_{t}=w b s_{t}
\end{aligned}
$$

where $\tilde{q}=q+\bar{r}$ is the excess return in deviation from steady state, $w=\sum_{j=1}^{T}\left(\bar{R}^{p}\right)^{j-1} / T$ and $\bar{R}^{p}=(1-b) e^{\bar{r}}+b$. The Technical Appendix also derives the steady-state market equilibrium condition:

$$
f \bar{b}^{A}+(1-f) \bar{b}^{I}+\frac{b}{T} \sum_{j=1}^{T}(T-j) \bar{r}(1-b)=w b
$$

where $\bar{b}^{A}$ and $\bar{b}^{I}$ are the steady state portfolios of attentives and inattentives:

$$
\begin{aligned}
& \bar{b}^{A}=b^{A}-\frac{\bar{r}}{\gamma \sigma_{A}^{2}(1+\phi)} \\
& \bar{b}^{I}=b^{I}-\frac{\bar{r} T}{\gamma \sigma_{I}^{2}+T \gamma \sigma_{A}^{2} \phi}
\end{aligned}
$$

Then we conjecture (16) with

$$
\begin{aligned}
& A(L)=a_{1}+a_{2} L+a_{3} L^{2}+\ldots \\
& B(L)=b_{1}+b_{2} L+b_{3} L^{2}+\ldots
\end{aligned}
$$

Substituting (16) into the market equilibrium condition (24), we obtain an equilibrium exchange rate equation. We then need to equate the conjectured to the equilibrium exchange rate equation, which allows us to solve for the parameters in the lag operators. As mentioned in the main text, we set the coefficients $a_{j}=0$ and $b_{j}=0$ for $j>L$. We then have $2 L+1$ non-linear equations to solve for $a_{1}, . ., a_{L}, b_{1}, . ., b_{L}$ and $\bar{r}: 2 L$ equations equating the conjectured to the equilibrium coefficients of the exchange rate equation and the steady state market equilibrium equation (25). Further algebraic details can be found in the Technical Appendix. In the application to quarterly data we set $L=60$. Increasing $L$ further has a negligible impact on results. 


\section{A.3 Threshold Information Processing Cost}

The function $\tau(f)$ is computed by equating the value functions of being attentive and inattentive. We describe this procedure below. The Technical Appendix describes each step in detail.

First consider an attentive investor born at date $t$, who makes investment decisions at all dates $t, . ., t+T-1$. We need to solve for the value function at date $t$. This is done by backward induction. We start with the known value function at $t+T, V_{t+T}=W_{t+T}^{1-\gamma} /(1-\gamma)$. We make an educated guess that the value function at date $t+j$ is

$$
V_{t+j}=(1-\tau)^{(1-\gamma)(T-j)} e^{v_{t+j}} W_{t+j}^{1-\gamma} /(1-\gamma)
$$

where $\tau$ is the information processing cost as a fraction of periodic wealth and $v_{t+j}$ depends on the state space $I_{t+j}=\left(\epsilon_{t+1}^{u}, . ., \epsilon_{t+j}^{u}, \epsilon_{t+1}^{x}, . ., \epsilon_{t+j}^{x}\right)^{\prime}$. It is immediate that $v_{t+T}=0$. We can solve the functions $v_{t+j}$ by backwards induction, using the Bellman equation

$$
V_{t+j}=\max _{b_{t+j}^{A}} E_{t+j} V_{t+j+1}
$$

where $b_{t+j}^{A}$ is the fraction invested in Foreign bonds.

In order to solve for $v_{t+j}$ for a known $v_{t+j+1}$ as a function of the state at $t+j+1$, first substitute (30) into (31), using

$$
W_{t+j+1}=R_{t+j+1}^{p} e^{-0.5 \gamma \sigma_{A}^{2} \phi\left(b_{t+j}^{A}-b\right)^{2}}(1-\tau) W_{t+j}
$$

It follows that

$$
e^{v_{t+j}}=\max _{b_{t+j}^{A}} E_{t+j}\left(R_{t+j+1}^{p} e^{-0.5 \gamma \sigma_{A}^{2} \phi\left(b_{t+j}^{A}-b\right)^{2}}\right)^{1-\gamma} e^{v_{t+j+1}}
$$

If we know the optimal portfolio $b_{t+j}^{A}$, this allows us to solve the time $t+j$ value function from the time $t+j+1$ value function.

We solve for the optimal portfolio in a way similar to that described in Appendix A.1, dropping terms from the first order condition that are higher than second order and therefore naturally disappear in continuous time. We leave a detailed description to the Technical Appendix. The solution to the optimal portfolio is very intuitive:

$$
b_{t+j}^{A}=b^{A}+\frac{E_{t+j}\left(q_{t+j+1}\right)}{\gamma \sigma_{A}^{2}(1+\phi)}+\frac{\operatorname{cov}\left(q_{t+j+1}, v_{t+j+1}\right)}{\gamma \sigma_{A}^{2}(1+\phi)}
$$


where $b^{A}$ is the constant term defined in (23). The optimal portfolio is therefore the same as derived for myopic investors, plus a hedge term that depends on the covariance between the excess return and $v_{t+j+1}$. The last term is new and reflects a hedge against the parameter $v_{t+j+1}$ of next period's value function, which will depend on next period's expected returns. In practice we find that even though the hedge term is non-zero and time-varying, it is swamped by the standard myopic portfolio term.

Having derived the optimal portfolio, we can solve the value function by backward induction using (33). In order to compute expectations, both in (33) and (34), we need to discretize the state space. A $N(0,1)$ distribution is approximated with $N$ equally spaced observations. Observation $i$ is

$$
m_{i}=-\frac{N-1}{2} n+n(i-1)
$$

where $n$ is the space between innovations. If $\Phi($.$) is the cumulative normal distri-$ bution, the probability $\pi(i)$ of observation $i$ is

$$
\begin{aligned}
& \pi_{1}=\pi_{N}=0.5\left(\Phi\left(m_{1}\right)+\Phi\left(m_{2}\right)\right) \\
& \pi_{i}=0.5\left(\Phi\left(m_{i+1}\right)-\Phi\left(m_{i-1}\right)\right) \quad i=2, . ., N-1
\end{aligned}
$$

We choose the step $n$ such that the standard deviation of this discretized distribution is 1 . If $N \rightarrow \infty$, the discrete distribution approaches the $N(0,1)$ distribution. Innovations in $x(u)$ are drawn from the discretized $N(0,1)$ distribution times standard deviation $\sigma_{x}\left(\sigma_{u}\right)$.

If $i_{1}$ and $i_{2}$ are the numbers of the innovations from the discretized normal distribution of respectively $\epsilon_{t+j+1}^{u}$ and $\epsilon_{t+j+1}^{x}$, the Bellman equation can be written as

$$
\begin{aligned}
& e^{v_{t+j}\left(I_{t+j}\right)}=\sum_{i_{1}=1}^{N} \sum_{i_{2}=1}^{N} \pi\left(i_{1}\right) \pi\left(i_{2}\right) e^{v_{t+j+1}\left(I_{t+j+1}\left(i_{1}, i_{2}\right)\right)} * \\
& \left(R_{t+j+1}^{p}\left(i_{1}, i_{2}\right) e^{-0.5 \gamma \sigma_{A}^{2} \phi\left(b_{t+j}^{A}-b\right)^{2}}\right)^{1-\gamma}
\end{aligned}
$$

Substituting the optimal portfolio (34), evaluated at the discretized state space, we can then solve for the period $t+j$ value function from the period $t+j+1$ value function. 
For an inattentive investor we have

$$
V_{t}=\max _{b_{t}^{I}} E_{t} V_{t+T}=\max _{b_{t}^{I}} E_{t} \frac{W_{t+T}^{1-\gamma}}{1-\gamma}
$$

An educated guess of the value function is

$$
V_{t}=e^{v^{I}} W_{t}^{1-\gamma} /(1-\gamma)
$$

We have

$$
W_{t+T}=\left[\prod_{j=1}^{T} R_{t+j}^{p}\right] e^{-\gamma \sigma_{A}^{2} \phi T\left(b_{t}^{I}-b\right)^{2}} W_{t}
$$

Therefore

$$
e^{v^{I}}=\max _{b_{t}^{I}} E_{t}\left(\prod_{j=1}^{T} R_{t+j}^{p}\right)^{1-\gamma} e^{-(1-\gamma) \gamma \sigma_{A}^{2} \phi T\left(b_{t}^{I}-b\right)^{2}}
$$

Following exactly the same method as described above for attentive investors we obtain the same portfolio as in (12). There is no dynamic hedge term since there is only one portfolio decision to make. Expectations and variances in the portfolio are now computed with respect to the discretized probability space. Given the solution for the optimal portfolio, the parameter $v^{I}$ from the time $t$ value function follows directly from (42).

Having solved for the value functions of both attentive and inattentive investors, it is now straightforward to compute the threshold information processing cost $\tau(f)$. It is such that an investor facing this information processing cost has the same expected utility whether attentive or inattentive. Equating attentive and inattentive time $t$ value function, when the investor is born, gives

$$
(1-\tau(f))^{(1-\gamma) T} e^{v_{t}}=e^{v^{I}}
$$

Therefore

$$
\tau(f)=1-e^{\frac{v^{I}-v_{t}}{T(1-\gamma)}}
$$

This is the cost per period. If there are 4 periods in a year, as we have assumed in the application to the data, then the annual threshold information processing cost in percentage terms is 400 times (44). Those numbers are reported in Table 2. 


\section{References}

[1] Bacchetta, Philippe, and Eric van Wincoop (2004), "A Scapegoat Model of Exchange Rate Determination," American Economic Review 94, 114-118.

[2] Bacchetta, Philippe, and Eric van Wincoop (2005), "Why Are Asset Returns Predictable? The Role of Rational Inattention," mimeo.

[3] Bacchetta, Philippe and Eric van Wincoop (2006), "Can Information Heterogeneity Explain the Exchange Rate Determination Puzzle?," American Economic Review, forthcoming.

[4] Bacchetta, Philippe, Elmar Mertens, and Eric van Wincoop (2005), "Predictability in FX, Stock and Bond Markets: What Does Survey Data Tell Us?," mimeo.

[5] Backus, David K., Silverio Foresi and Chris I. Telmer (2001), "Affine Term Structure Models and the Forward Premium Anomaly," Journal of Finance 56(1), 279-304.

[6] Baldwin, Richard E. (1990), "Re-interpreting the Failure of Foreign Exchange Market Efficiency Tests: Small Transaction Costs, Big Hysteresis Bands," NBER Working Paper 3319.

[7] Barberis, Nicholas (2000), "Investing for the Long Run when Returns Are Predictable," Journal of Finance LV, 225-265.

[8] Bekaert, Geert, Robert J. Hodrick and David Marshall (1997), "The Implications of First Order Risk Aversion for Asset Market Risk Premiums," Journal of Monetary Economics 40, 3-39.

[9] Bank for International Settlements (BIS) (2004), "Triennal Central Bank Survey of Foreign Exchange and Derivative Market Activity in April 2004".

[10] Campbell, John Y. and Motohiro Yogo (2004), "Efficient Tests of Stock Return Predictability," working paper, Harvard University. 
[11] Campbell, John. Y. and Luis M. Viceira (1999), "Consumption and Portfolio Decisions when Expected Returns are Time Varying," Quarterly Journal of Economics May, 433-495.

[12] Carroll, Christopher D. (2003), "Macroeconomic Expectations of Households and Professional Forecasters," Quarterly Journal of Economics 118(1), 269298.

[13] Chaboud, Alain P. and Jonathan H. Wright (2005), "Uncovered Interest Rate Parity: It Works, But Not For Long," Journal of International Economics 66(2), 349-362.

[14] Chinn, Menzie D. and Guy Meredith (2005), "Testing Uncovered Interest Parity at Short and Long Horizons During the post-Bretton Woods Era," NBER Working paper 11077.

[15] Chinn, Menzie and Jeffrey Frankel (2002), "Survey Data on Exchange Rate Expectations: More Currencies, More Horizons, More Tests," in W. Allen and D. Dickinson, eds., Monetary Policy, Capital Flows and Financial Market Developments in the Era of Financial Globalization: Essays in Honor of Max Fry, London: Routledge, 145-167.

[16] Duffie, Darrell and Tong-sheng Sun (1990), "Transactions Costs and Portfolio Choice in a Discrete-Continuous-Time Setting," Journal of Economic Dynamics and Control," 14, 35-51.

[17] Engel, Charles (1996), "The Forward Discount Anomaly and the Risk Premium: A Survey of Recent Evidence," Journal of Empirical Finance 3, 123192.

[18] Engel, Charles and Kenneth D. West (2005), "Exchange Rates and Fundamentals," Journal of Political Economy, 113, 485-517.

[19] Engel, Charles and Akito Matsumoto (2005), "Portfolio Choice in a Monetary Open-Economy DSGE Model," working paper, University of Wisconsin.

[20] Fama, Eugene F. (1984), "Forward and Spot Exchange Rates," Journal of Monetary Economics 14, 319-338. 
[21] Fisher, Eric O’N. (2005), "The Forward Premium in a Model with Heterogeneous Prior Beliefs," working paper, Ohio State University.

[22] Flood, Robert and Andrew K. Rose (2002), "Uncovered Interest Parity in Crisis," IMF Staff Papers 49(2), 252-266.

[23] Froot, Kenneth A. (1990), "Short Rates and Expected Asset Returns," NBER Working Paper No. 3247.

[24] Froot, Kenneth A. and Jeffrey A. Frankel (1989), "Forward Discount Bias: Is it an Exchange Risk Premium?" Quarterly Journal of Economics 104, February, 139-161.

[25] Froot, Kenneth A., Paul G.J. O’Connell, and Mark S. Seasholes (2001), "The Portfolio Flows of International Investors" Journal of Financial Economics 59, 151-193.

[26] Froot, Kenneth A. and Richard H. Thaler (1990), "Anomalies: Foreign Exchange," Journal of Economic Perspectives 4(3), 179-192.

[27] Gabaix, Xavier, David Laibson, Guillermo Moloche, and Stephen Weinberg (2003), "The Allocation of Attention: Theory and Evidence," mimeo.

[28] Gourinchas, Pierre-Olivier and Aaron Tornell (2004), "Exchange Rate Puzzles and Distorted Beliefs," Journal of International Economics 64, 303-333.

[29] Kandel, Shmuel, and Robert F. Stambaugh (1996), "On the Predictability of Stock Returns: An Asset-Allocation Perspective," Journal of Finance LI, 385-424.

[30] Lewis, Karen K. (1995), "Puzzles in International Financial Markets," in Gene M. Grossman and Kenneth Rogoff (eds), Handbook of International Economics (Amsterdam, Elsevier Science), 1913-1971.

[31] Liu, Wei, and Alex Maynard (2005), "Testing Forward Rate Unbiasedness Allowing for Persistent Regressors," Journal of Empirical Finance, forthcoming.

[32] Lynch, Anthony W. (1996), "Decision Frequency and Synchronization Across Agents: Implications for Aggregate Consumption and Equity Return," The Journal of Finance 51(4), 1479-1497. 
[33] Lyons, Richard K. (2001), The Microstructure Approach to Exchange Rates, MIT Press, (Cambridge, Massachusetts).

[34] Mackowiak, Bartosz and Mirko Wiederholt (2004), "Optimal Sticky Prices under Rational Inattention," working paper, Humboldt University Berlin.

[35] Mankiw, Gregory and Ricardo Reis (2002), "Sticky Information versus Sticky Prices: A Proposal to Replace the New Keynesian Phillips Curve," Quarterly Journal of Economics 117, 1295-1328.

[36] Mark, Nelson and Yangru Wu (1998), "Rethinking Deviations from Uncovered Interest Parity: The Role of Covariance Risk and Noise," The Economic Journal 108, 1686-1706.

[37] McCafferty, Stephen and Robert Driskill (1980), "Problems of Existence and Uniqueness in Nonlinear Rational Expectations Models," Econometrica 48, 1313-1317.

[38] McCallum, Bennett T. (1994), "A Reconsideration of the Uncovered Interest Rate Parity Relationship," Journal of Monetary Economics 33, 105-132.

[39] Moscarini, Giuseppe (2004), "Limited Information Capacity as a Source of Inertia," Journal of Economic Dynamics and Control, 28(10), 2003-2035.

[40] Peng, Lin and Wei Xiong (2005), "Investor Attention, Overconfidence and Category Learning," forthcoming Journal of Financial Economics.

[41] Reis, Ricardo (2004a), "Inattentive Consumers," NBER Working Paper No. 10883.

[42] Reis, Ricardo (2004b), "Inattentive Producers," NBER Working Paper No. 10883.

[43] Sarno, Lucio, Giorgio Valente and Hyginus Leon (2004), "The Forward Discount Puzzle and Nonlinearity in Deviations from Uncovered Interest Parity: A New Perspective," working paper, University of Warwick.

[44] Sarno, Lucio (2005), "Towards a Solution to the Puzzles in Exchange Rate Economics: Where do we Stand?," Canadian Journal of Economics 38(3), 673-708. 
[45] Sims, Chris (2003), "Implications of Rational Inattention," Journal of Monetary Economics 50, 665-690.

[46] Sims, Chris (1998), "Stickyness," Carnegie-Rochester Conference Series on Public Policy 49, 317-356.

[47] Stambaugh, Robert F. (1999), "Predictive Regressions," Journal of Financial Economics 54, 375-421.

[48] Woodford, Michael (2003), Interest and Prices: Foundations of a Theory of Monetary Policy, Princeton University Press (Princeton). 


\begin{tabular}{|c|c|c|c|c|c|}
\hline $\begin{array}{r}\mathrm{F} \\
\Delta s_{t+1}-f d_{t}= \\
\text { Average slope }\end{array}$ & $\begin{array}{l}\text { nel A } \\
\alpha+\beta \\
\text { of sys }\end{array}$ & $\begin{array}{l}\text { Predicta } \\
d_{t}+\varepsilon_{t+1} \\
\text { em with }\end{array}$ & $\begin{array}{l}\text { Excess R } \\
1978.11- \\
\text { urrencies }\end{array}$ & $\begin{array}{l}\text { turns } \\
2004.1 \\
\text { gainst }\end{array}$ & dollar) \\
\hline \multicolumn{3}{|c|}{ Equal Weights } & \multicolumn{3}{|c|}{ GDP Weights } \\
\hline$\beta$ & $\sigma(\beta)$ & $R^{2}$ & $\beta$ & $\sigma(\beta)$ & $R^{2}$ \\
\hline$-2.80^{* * *}$ & 0.56 & 0.11 & $-3.17^{* * *}$ & 0.58 & 0.12 \\
\hline \multicolumn{6}{|c|}{$\begin{array}{l}s_{t+1}-s_{t+1}^{e}=\alpha+\beta f d_{t}+\varepsilon_{t+1} \quad 1986.8-2004.10 \\
\text { Average slopes of system with } 5 \text { currencies (against US dollar) }\end{array}$} \\
\hline \multicolumn{3}{|c|}{ Equal Weights } & \multicolumn{3}{|c|}{ GDP Weights } \\
\hline$\beta$ & $\sigma(\beta)$ & $R^{2}$ & $\beta$ & $\sigma(\beta)$ & $R^{2}$ \\
\hline$-1.89^{* * *}$ & 0.73 & 0.052 & $-1.37^{* * *}$ & 0.64 & 0.032 \\
\hline
\end{tabular}

The five currencies are the German mark, British pound, Japanese yen, Canadian dollar, and Swiss franc. Panel A: Currency spot rates are end-of-period rates from IFS. $\Delta s_{t+1}$ refers to the 3-month change in the $\log$ exchange rate. The forward discount is equal to the interest rate differential. Interest rates are 3-month rates as quoted in the London Euromarket and were obtained from Datastream (Thomson Financial). Panel B: Exchange rate expectations are based on survey data of 3-month exchange rate expectations by 43 large financial institutions, compiled monthly since 1986 by Forecasts Unlimited, Inc. The survey is answered each month over a period of three business days. The spot rate $s_{t+1}$ is the average log-spot exchange rate over the three business days of the survey response plus 3 months. Standard errors of the average slopes are computed from the (asymptotically) multivariate normal distribution of the slope estimates. This distribution is estimated from a SUR estimation of the five regressions using the robust Newey-West with 4 lags. Coefficients with a significance of $1 \%$ are denoted by $* * *$.

Table 1: Predictability of Excess Returns and Expectational Errors 


\begin{tabular}{|c|c|c|c|c|c|c|}
\hline & $\begin{array}{l}\text { benchmark } \\
T=5, f=0.05 \\
\phi=10, \rho_{x}=0.5\end{array}$ & $f=0$ & $f=0.1$ & $f=1$ & $T=8$ & $T=3$ \\
\hline & & \multicolumn{5}{|c|}{ Panel A: hold $\sigma_{x}$ constant } \\
\hline $\begin{array}{l}\text { excess return predictability: } \\
\text { coefficient } \beta \text { of regression } \\
\Delta s_{t+1}-f d_{t}=\alpha+\beta f d_{t}\end{array}$ & -1.74 & -6.51 & -0.57 & -0.29 & -6.09 & -0.55 \\
\hline $\begin{array}{l}\text { bias due to inattention } \\
\text { (compare to bias for } f=1 \text { ) }\end{array}$ & -1.45 & -6.22 & -0.28 & 0 & -5.80 & -0.26 \\
\hline $\begin{array}{l}\text { predictable expectational errors } \\
\text { coefficient } \beta \text { of regression } \\
\Delta s_{t+1}-\bar{E}_{t}\left(\Delta s_{t+1}\right)=\alpha+\beta f d_{t}\end{array}$ & -0.80 & -4.08 & -0.07 & 0 & -4.11 & -0.08 \\
\hline $\begin{array}{l}\text { unconditional standard } \\
\text { deviation } s_{t+1}-s_{t}(\%)\end{array}$ & 5.70 & 16.85 & 3.13 & 2.76 & 16.2 & 3.20 \\
\hline $\begin{array}{l}\text { conditional standard } \\
\text { deviation } s_{t+1}-s_{t}(\%)\end{array}$ & 4.17 & 12.50 & 2.83 & 2.72 & 12.8 & 2.79 \\
\hline $\begin{array}{l}\text { threshold information processing } \\
\text { cost } \tau(f) \text { (percent per year) }\end{array}$ & 2.38 & 2.25 & 0.63 & 0.02 & 2.01 & 0.63 \\
\hline & & \multicolumn{5}{|c|}{$\begin{array}{l}\text { Panel B: hold unconditional standard } \\
\text { deviation } s_{t+1}-s_{t} \text { constant at } 5.70 \%\end{array}$} \\
\hline $\begin{array}{l}\text { excess return predictability: } \\
\text { coefficient } \beta \text { of regression } \\
\Delta s_{t+1}-f d_{t}=\alpha+\beta f d_{t}\end{array}$ & -1.74 & -1.95 & -1.67 & -1.50 & -1.88 & -1.61 \\
\hline $\begin{array}{l}\text { bias due to inattention } \\
\text { (compare to bias for } f=1 \text { ) }\end{array}$ & -1.45 & -1.66 & -1.38 & 0 & -1.59 & -1.32 \\
\hline $\begin{array}{l}\text { predictable expectational errors } \\
\text { coefficient } \beta \text { of regression } \\
\Delta s_{t+1}-\bar{E}_{t}\left(\Delta s_{t+1}\right)=\alpha+\beta f d_{t}\end{array}$ & -0.80 & -0.84 & -0.72 & 0 & -0.95 & -0.60 \\
\hline$\sigma_{x}(\%)$ & 4.29 & 1.95 & 5.82 & 20.13 & 3.26 & 6.64 \\
\hline $\begin{array}{l}\text { conditional standard } \\
\text { deviation } s_{t+1}-s_{t}(\%)\end{array}$ & 4.17 & 3.51 & 4.36 & 4.98 & 4.41 & 3.91 \\
\hline $\begin{array}{l}\text { threshold information processing } \\
\text { cost } \tau(f) \text { (percent per year) }\end{array}$ & 2.38 & 2.72 & 2.09 & 0.96 & 2.23 & 2.30 \\
\hline
\end{tabular}

Table 2: Excess Return Predictability in the Model 
Figure 1 Delayed Overshooting--Impulse Response Exchange Rate to Interests Rate Shock*

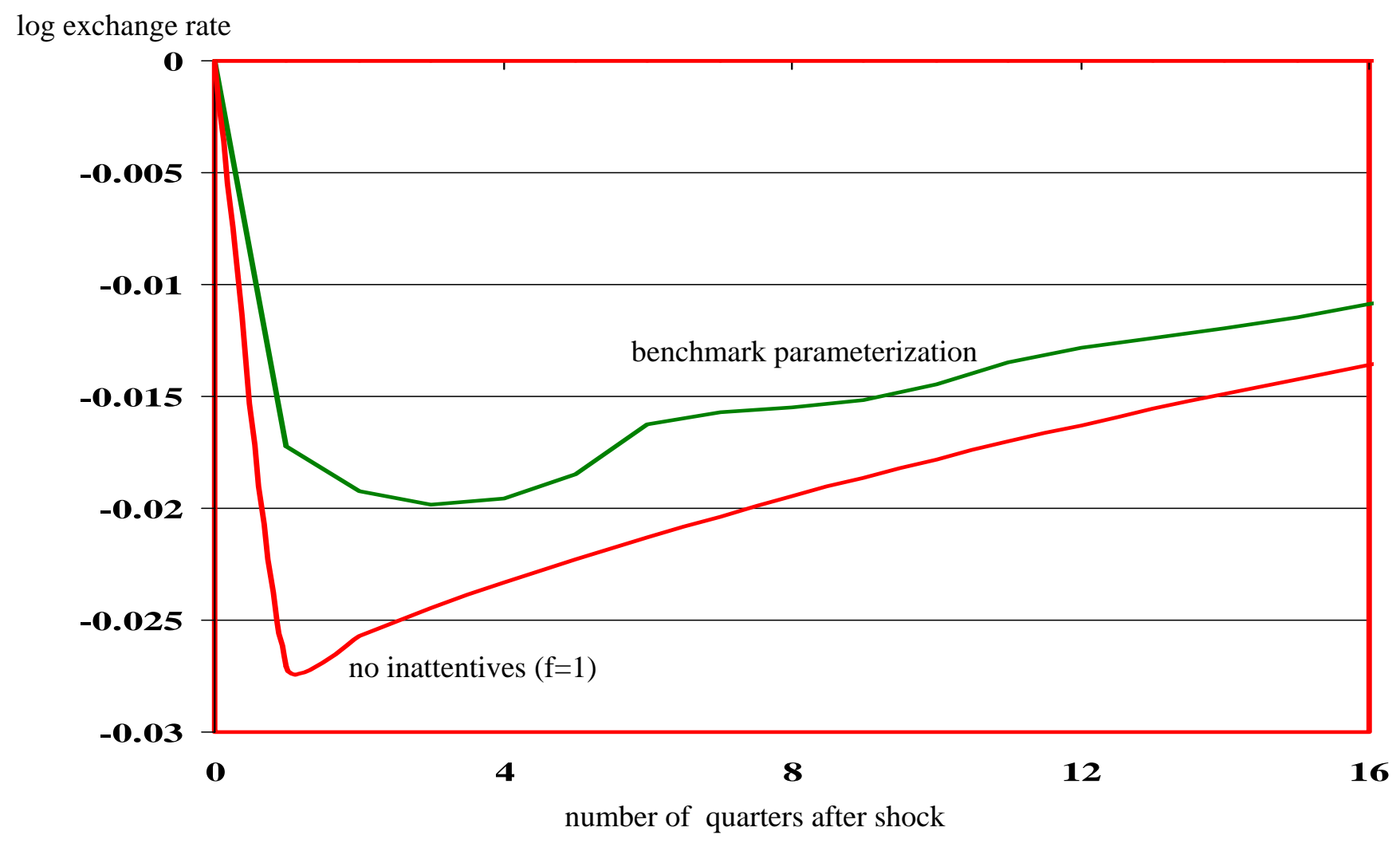

*The figure shows the impulse response of the log exchange rate to a one standard deviation interest rate shock (decrease in the foreign interest rate) for both the benchmark parameterization and the case of no inattentives. For the latter we set $\mathrm{f}=1$ and leave other parameters the same as under the benchmark parameterization. 


\section{Figure 2 Impulse Responses to Interests Rate and Supply Shocks*}

Panel A Impulse response to one standard deviation interest rate shock

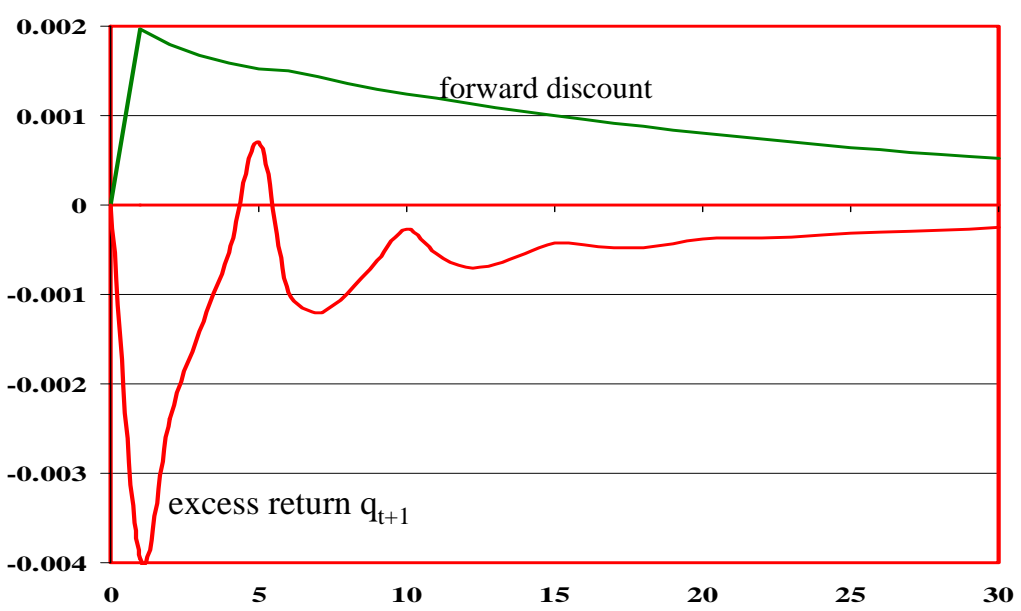

Panel B Impulse response to one standard deviation interest rate shock

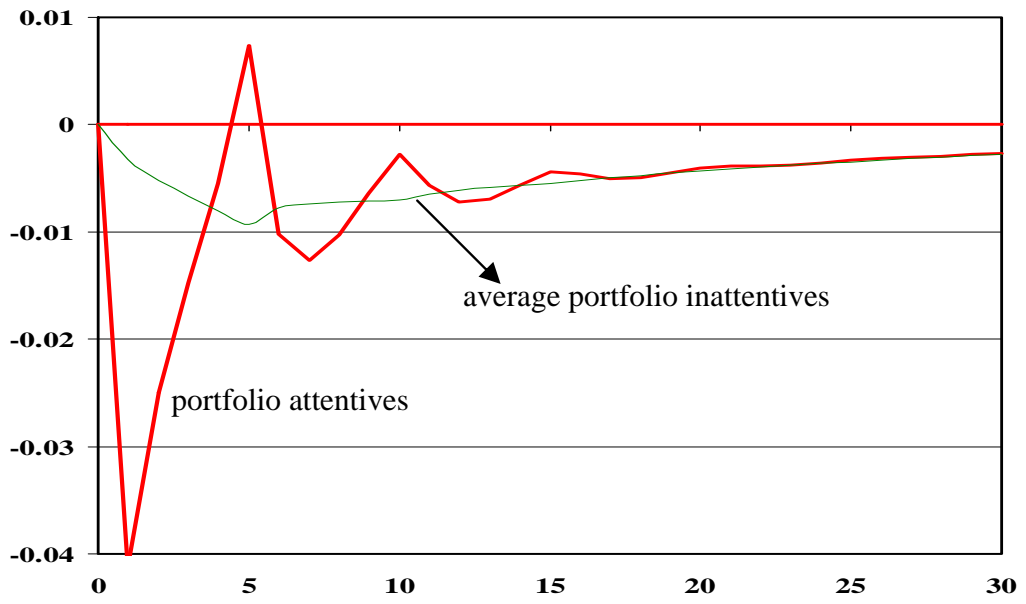

Panel C Impulse response to one standard deviation supply shock

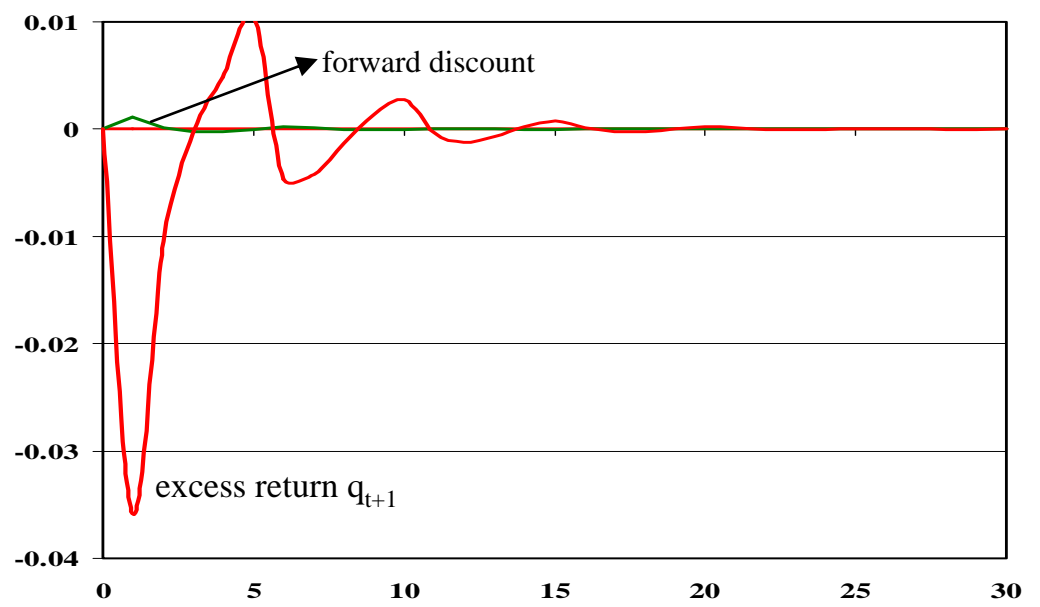

Panel D Impulse response to one standard deviation supply shock

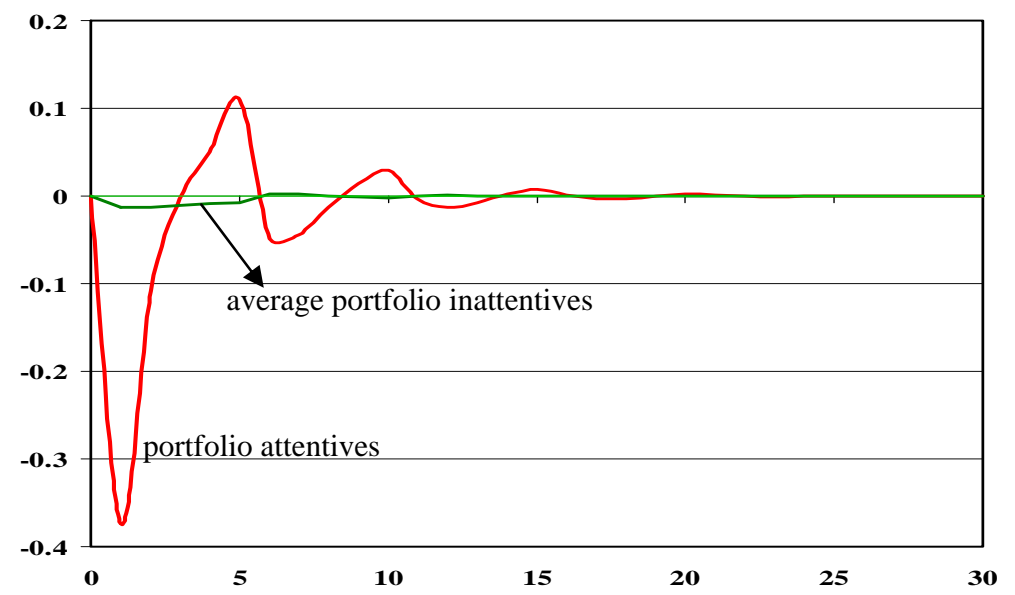

